\title{
Relationship between Customer and Management Knowledge Based of Life Cycle Concept
}

\section{Emin Neziraj PhD c.}

Teacher of University "Haxhi Zeka" Business Faculty, Pec, Kosova

Prof.Dr. Justina Shiroka Pula

Teacher of University "Hasan Prishtina" Economis Faculty, Pristina, Kosova

Dr.Driton Sylqa

Teacher of University "Haxhi Zeka" Business Faculty, Pec, Kosova

\section{Doi:10.5901/ajis.2014.v3n2p117}

\section{Abstract}

Modern business world,, the role of consumer knowledge plays an important role in developing a knowledge management in SME respectively in industry sales industry of wholesalers and retailers. With that developed countries, the management team their knowledge harmonizes with the needs of consumers consumer knowledge. Exactly relations between of consumers and management in themselves owns series of problems which need to be resolved to an effective way. This relation in SME by transition countries has not been developed to the level as in the developed countries. Therefore, research is necessary in the SME of countries in transition, which shall first of all to determine level of relations between the consumer and the of the management team of SME the relationship the consumer of knowledge and the of knowledge of management team. Regarding to the main reason of studies and also with the problematic situations research paper require the theoretical model witches divided into two parts The first part of theatrical model is discussion about topics which is quit significant with studies areas as: Knowledge cycle based view with the main elements such are theoretical approach by creation knowledge, capture knowledge and etc. The second part of theoretical background is discussion about customer knowledge on the relation with management cycle and their segments. Empirical data of this research include the total representative number of 323 correspondents where are 253 male and 70 female, according to the statistical method of obtaining a sample size where is expedited $P=30 \%$ therefore Suggestion precision $d=0.05$. According to the Questionnaires were gathered after completion and were analyzed by SPSS Software, which caring up the results of research variables which means regression analyzes with ANOVAs model will show $P=0,35$. The regression coefficient give us the discussion between following Hypothesis $H O$ Knowledge management is in relation with client knowledge in industry of wholesalers and retailers $\mathrm{H} 1 \mathrm{Knowledge} \mathrm{management} \mathrm{is} \mathrm{not} \mathrm{in} \mathrm{relation} \mathrm{with} \mathrm{client}$ knowledge industry of wholesalers and retailers. And finally results will give explain about econometric parameters $p=0,35$ and $\varepsilon=0,0356$.

Keywords: Management knowledge, Cycle knowledge, Relation customer

\section{Introduction}

\subsection{Problem Discussion}

In the twenty-first-century landscape, firms must compete in a complex and challenging context that is being transformed by many factors, from globalization, technological development, and increasingly rapid diffusion of new technology, to the development and use of knowledge (Hitt, Keats, \& DeMarie, 1998). This new landscape requires firms to do things differently in order to survive and prosper. Specifically, they must look to new sources of competitive advantage and engage in new forms of competition. This, in turn, requires a clear understanding of the nature of competition and competitive dynamics.

One popular approach to understanding competitive dynamics is the resource-based view of the firm. According to this view, the explanation for why some firms ultimately succeed and others fail can be found in understanding their resources and capabilities. A firm's resources and capabilities influence both the strategic choices that managers make and the implementation of those chosen strategies. (The recent debate over this model suggests there are challenges 
involved in applying it; see Priem \& Butler, 2001; Barney, 2001.).

To understand why certain competitive strategies are more effective than others, one must consider the distribution of resources in competing firms. Although a given firm may possess more orless of any particular resource, only those resources that are rare, valuable, and difficult to imitate provide a sustainable competitive advantage (Amit \& Schoemaker, 1993; Barney, 1991; Schoenecker \& Cooper, 1998). When the strategies employed are successful in leveraging the firm's rare, valuable, and difficult-to-imitate resources, that firm is likely to gain an advantage over its competitors in the marketplace and thus earn higher returns (Hitt, Nixon, Clifford, \& Coyne, 1999). Competitive advantages that are sustained over time lead to higher performance (Peteraf, 1993).

\subsection{Research question}

\subsection{Hypothesis}

Main hypothesis: There is a meaningful relation between knowledge management and customer relationship management in wholesalers industry.

Subsidiary hypothesis 1: There is a meaningful relation between possession of knowledge and customer relationship management in wholesalers industry.

Subsidiary hypothesis 2: There is a meaningful relation between saving and customer relationship management in wholesalers industry.

Subsidiary hypothesis 3: there is a meaningful relation between processing and customer relationship management in wholesalers industry.

Subsidiary hypothesis 4: There is a meaningful relation between knowledge transmission and customer relationship management in wholesalers industry.

\subsection{Methodology}

We will start with the presentation of my scientific approach, which is based on different research methods. First in this research will use the quantities research which starts with existing theoretical model which dedicates to relation between customers knowledge and management cycle concept of knowledge, the curing up the research questions. Empirical data of this research include the total representative number of 323 correspondents where are 253 male and 70 female, according to the statistical method of obtaining a sample size where is expedited $\mathrm{P}=30 \%$ therefore Suggestion precision $d=0.05$

\section{Theoretical Background}

\subsection{Knowledge based competition}

The notion of knowledge-based competition has gained significant attention in recent years (Grant, 1996; Liebeskind, 1996), with scholars focusing on how firms create, transfer, and leverage knowledge

for competitive advantage. And although there are many reasons for the success of firms competing on knowledge, human capital is at least in part a foundation for core competencies and an underlying source of competitive success (DeNisi, Hitt, \& Jackson,Chapter One, this volume; Hitt, Bierman, Shimizu, \& Kochhar, 2001; Wright, Dunford, \& Snell, 2001). Yet whereas all people contribute knowledge, innovation, creativity, and the like, not all employees are equal in their knowledge-based contributions.

Virtually all work performed in firms requires employees to use some knowledge and skill. Organizations must manage a wide assortment of employees; some contribute based on the knowledge they possess whereas others contribute based on the jobs they do (see, for example, Drucker, 1999). The challenge that organizations face is this: there are important distinctions between managing traditional work and managing knowledge work.

Identifying these differences, and perhaps more importantly, understanding how to manage them, may be crucial for building competitive capability. In some ways, the new focus on managing the knowledge of a firm's workforce represents a departure for human resource management. Traditionally, the field has viewed the job, rather than knowledge, as the fundamental unit of analysis. We believe that shifting our emphasis from job management to knowledge management-that is, to what people know and how they use that knowledge—may have significant 
implications for HRM research and practice. One possible way to address these issues is to view a firm as a portfolio of multiple types of human capital that range in the kinds and levels of knowledge used to perform jobs. Once this distinction is made, we can address issues fundamental to the management of knowledge workers as well as to the management of other types of workers.

Successful knowledge management applies a set of approaches to organizational knowledge including its accumulation, utilization, sharing and ownership.

- Accumulation: the higher the effectiveness of knowledge accumulation (internal, external;

- through internalization or externalization) in an organization, the greater the KM effect ;

- Utilizations: the higher the effectiveness of utilizing the (existing) knowledge in an organization, the better the KM result ;

- Sharing: the improvement of sharing of knowledge (formal or informal) effects the

- KM positively ;

- Ownership: the better the accessibility of knowledge, the greater the KM success.

\subsection{Customer Knowledge Management (CKM)}

Customer Knowledge Management (CKM) refers to the management of customer knowledge (Rowley, 2002). By understanding the customers' needs and wants, it is important for businesses to streamline processes, products and services in order to build sustainable customer relationships. However, this understanding must be shared among departments because organization consists of interdependent units, working together to serve the customers. Sharing the customer knowledge as one type of knowledge sharing can help firms to identify present and latent customer needs. Until now, most companies have focused on collecting vast amounts of data about their customers, but they do not know how to deal with them (Davenport, 2001).

The concept of CKM has been firstly advocated by Gibbert, Leibold, and Probst (2002), who describe CKM as the strategic process by which cutting edge companies emancipate their customers from passive recipient of products and services, to empowerment as knowledge partners. They said that CKM is about getting, sharing, and expanding customer knowledge that resides in, to both customer and corporate benefits. It can take the form of prosumerism, joint innovation, with team-based learning, communities of practice, and joint intellectual property (IP) management. In their paper, CKM reflects customer knowledge management, the knowledge that resides in the client, in contrast to the knowledge of the customer, which is the classical knowledge used in Customer Relationship Management (CRM) system. The second is Gebert, Gelb, Kolbe, and Brenner (2002) from University of St. Gallen, who develop their CKM concept through reflections on CRM and the use of knowledge gathered to support business processes. The task of CKM, as highlighted by them, is to design the knowledge flow inside and between the CRM processes and to allocate relevant knowledge gained from customer-related processes to others. Three main dimensions of CK are classified in their studies known as knowledge for customers, knowledge about customers, and knowledge from customers.

Knowledge about customers refers to customer segments and individual customers. It can be captured through customer surveys, service management and customer complaints. It is accumulated to understand motivations and to address customers in a personalized way. Knowledge about customers also includes demographic data, customer history, contacts, needs, expectations and buying patterns. It is necessary to manage data on a continuous basis; otherwise, they quickly become worthless. Knowledge about customers should lead to improvements in the effectiveness and efficiency of the internal business processes, for examples, the productivity of customer service representative; the reduction in learning curve, and the acceleration of product and service projection.

Knowledge for customers is generated in the process within the enterprise, such as research and development. It is required in the CRM process to meet the needs of customer. In other words, this knowledge is produced from organizations to customers and suppliers. For example, the organization will provide knowledge about product and knowledge about market and suppliers to customers so that the customers become aware of the current trend in the market.

Knowledge from customers is the knowledge captured from the customer database. Customers get their own expertise while using the product or service at the same time improving the customer experience with the firm.

During the interaction with the customer, this knowledge can be gathered to feed continuous improvement, such as improvements or new product development. No matter what the client knowledge is collected, it is important to manage and organize it properly. As a result, organization can develop partnerships with customers to produce innovative products and services that can improve organizational performance. 


\section{Methodology}

Current study is categorized as an applied descriptive study according to its target and based on its subject and structure of its hypotheses. The target is to describe conditions and phenomena. These phenomena include aspects of knowledge management and its relation with customer relationship management in the banks. As this study considers the effect of KM on CRM, the research is categorized as correlative studies. In this order, Pierson methodology is used and independent variable of KM and dependent variable of CRM and their various aspects are considered. Study hypotheses are described as below according to the target, method and variables:

According to history and literature of this study and its hypotheses, information management is considered as a independent variable and these aspects are considered for assessment: possession of knowledge, saving, processing and knowledge transmission. According to the model of Suini's group, any relationship with customers includes collaborative, operational and analytical aspects. Authors have deleted collaborative indicator which was for customers and have considered operational and analytical aspects which are specialized for employees and technical experts to consider customer relationship management as a dependent variable.

\subsection{Descriptive achievements of study}

Considering situation of variables of research: To assess and evaluate the variable of knowledge management level in study wholesalers industry, the four aspects (possession of knowledge, saving, processing and knowledge transmission) were used. This variable includes 22 characteristics in ordinal level of measurement and in Likert spectrum and is designed with five multiple choices. A distance variable - with amplitude of 88 - was calculated after summing up grade characteristics. refers to high level of knowledge management and 22 refers to low level. According to table 1, it can be said that knowledge management in study organizations is almost beneath the mean level (mean=63.5). Knowledge management level in these four aspects is represented in table 2.

Table 1. Descriptive statistics about knowledge management

\begin{tabular}{|l|c|c|c|c|c|c|}
\hline Descriptive statistics for independent variable & $\begin{array}{c}\text { Standard } \\
\text { deviation }\end{array}$ & Variance & $\begin{array}{c}\text { Min } \\
\text { statistics }\end{array}$ & $\begin{array}{c}\text { Max } \\
\text { statistics }\end{array}$ & Mean & Total \\
\hline Knowledge management & 3.41 & 11.78 & 54 & 72 & 63.5 & 294 \\
\hline Possession of knowledge & 2.4 & 5.6 & 12 & 23 & 16.9 & 294 \\
\hline Saving & 1.9 & 3.4 & 22 & 31 & 27.04 & 294 \\
\hline Processing & 1.11 & 3.8 & 5 & 12 & 9.03 & 294 \\
\hline Transmission of knowledge & 0.985 & 0.991 & 7 & 11 & 9.6 & 294 \\
\hline
\end{tabular}

Totally, the two aspects (operational and analytical aspects) were used to assess and measure customer relationship management in wholesalers. This variable includes 26 characteristics in the level of ordinal assessment and according to Likert spectrum with 5 multiple choices. A distance variable - with amplitude of 100 - was calculated after summing up grade characteristics. 125 refers to high level of customer relationship management and 25 refers to low level. According to table 2, it can be said that customer relationship management in study banks is almost above the mean level (mean=88.5). Customer relationship management level in two operational and analytical aspects is represented in table 2.

Table 2. Descriptive statistics about customer relationship management

\begin{tabular}{|l|c|c|c|c|c|c|}
\hline Descriptive statistics for independent variable & $\begin{array}{c}\text { Standard } \\
\text { deviation }\end{array}$ & Variance & $\begin{array}{c}\text { Min } \\
\text { statistics }\end{array}$ & $\begin{array}{c}\text { Max } \\
\text { statistics }\end{array}$ & Mean & Total \\
\hline Human power efficiency & 9.4 & 85.19 & 69 & 115 & 88.5 & 294 \\
\hline Operational aspect & 8.6 & 73.8 & 32 & 75 & 53.2 & 294 \\
\hline Analytical aspect & 3.5 & 3.6 & 27 & 43 & 28.2 & 294 \\
\hline
\end{tabular}

\subsection{Hypothesis test:}

To consider hypotheses in study wholesalers industry, Pierson test was used and the results are represented in table 3. 
Subsidiary hypothesis 1: There is a meaningful relation between possession of knowledge and customer relationship management in wholesalers industry.

The results of Pierson R-test indicate that there is a meaningful correlation (sig $=0.000)$ between possession of knowledge and customer relationship management. The total results say that more positive conception of personnel to possess knowledge, increases success of customer relationship management in banks. The correlation between two variables is linear and both of them will increase or decrease at a time. Correlation intensity between two variables is strong $(\mathrm{R}=0.518)$; $\mathrm{so}$, the hypothesis is approved temporarily.

Subsidiary hypothesis 2: There is a meaningful relation between saving and customer relationship management in wholesalers industry. There is a meaningful correlation $(\mathrm{sig}=0.000)$ between saving and customer relationship management. The total results say that more positive conception of personnel to saving, increases success of customer relationship management in banks. The correlation between two variables is linear and both of them will increase or decrease at a time. Correlation intensity between two variables is strong $(R=0.204)$; so, the hypothesis is approved temporarily.

Subsidiary hypothesis 3 : There is a meaningful relation between processing and customer relationship management in wholesalers industry. There is a meaningful correlation (sig $=0.000)$ between processing and customer relationship management. The total results say that more positive conception of personnel to processing, increases success of customer relationship management in banks. The correlation between two variables is linear and both of them will increase or decrease at a time. Correlation intensity between two variables is strong ( $R=0.483)$; so, the hypothesis is approved temporarily.

Subsidiary hypothesis 4: There is a meaningful relation between knowledge transmission and customer relationship management in wholesalers industry. There is not a meaningful correlation (sig=0.301) between knowledge transmission and customer relationship management. The total results say that conception of personnel about knowledge transmission has no effect on customer relationship management in banks; so, the hypothesis is approved temporarily.

Main hypothesis: There is a meaningful relation between knowledge management and customer relationship management in study wholesalers industry. The results of Pierson test indicate that variables of knowledge management and customer relationship management have a relationship of $\mathrm{R}=0.71$ in banks of Khuzestan Province and it can be said that correlation intensity between two variables is 0.71 which is a very strong level. The correlation between these two variables is direct (positive) and meaningfulness level (sig=0.000) is less than research alpha $(\alpha=0.05)$ which refers to a meaningful relationship between these two variables; so, the main hypothesis of study is approved temporarily. It can be said according to these achievements, the higher conception of personnel about knowledge management will improve customer relationship management in Khuzestan province. Higher conception of knowledge management, customer relationship management in banks is elevating positively.

Table 3. Relationship correlation test between organizational justice and human power efficiency

\begin{tabular}{|l|c|c|c|}
\hline & Correlation coefficient & Meaningfulness level & Results \\
\hline Subsidiary hypothesis 1 & 0.518 & 0 & approved \\
\hline Subsidiary hypothesis 2 & 0.204 & 0 & approved \\
\hline Subsidiary hypothesis 3 & 0.483 & 0 & approved \\
\hline Subsidiary hypothesis 4 & 0.201 & 0.301 & Rejected \\
\hline Main hypothesis & 0.71 & 0 & approved \\
\hline
\end{tabular}

Fitness model of explaining factors of customer relationship management To define fitness of this model, aspects of knowledge management (knowledge possession, saving, processing and knowledge transmission) which are measured in distance assessment level were inserted into the equation as independent variables. In this study, multi-variable regression analysis is done by means of step-tostep method. The results of regression analysis refer to explaining factors of customer relationship management which are inserted among all independent variables. In total model, all variables are inserted in regression equation and explain almost 0.542 percent of changes of dependant variable. According to statistics of table 5 it can be indicated that multiply correlation coefficient is $0.74(\mathrm{MR}=0.74)$ and its square root is 0.548 ; so, three dimensions of positive concept of employees of knowledge possession, saving and processing, purely include 0.542 of customer relationship management variance in study organizations. Other variances can be explained by external and unknown factors which are not included in this study. Knowledge possession is the most important factor which is more effective than others. 
Table 5. Multivariable regression analysis statistics of customer relationship management

\begin{tabular}{|c|c|c|}
\hline Multiply correlation coefficient & R-square explain coefficient & Adjusted R-square \\
\hline 0.72 & 0.548 & 0.542 \\
\hline
\end{tabular}

Table 6. Multivariable regression analysis statistics customer relationship management

\begin{tabular}{|l|c|c|c|c|c|}
\hline Resource of changes & Level of freedom & Sum of squares & Mean of squer & F statistics & Meaningfulness \\
\hline Regression effect & 4 & 3061.563 & 765.391 & 88.117 & 0 \\
\hline Remainder & 291 & 2527.65 & 8.686 & & \\
\hline Total & 295 & 5589.213 & -- & & \\
\hline
\end{tabular}

The results of variance analysis show that explaining variables are meaningfully able to foresee the changes of dependant variable (customer relationship management); in other words, AR explaining model is an adjusted meaningful model.

Table 7. Statistics of independent variables, inserted into regression model (remained regression in the model)

\begin{tabular}{|l|c|c|c|c|c|}
\hline Variable & B & Std.B & Beta & T & SigT \\
\hline Intercept & 5.619 & 4.025 & - & 1.396 & 0 \\
\hline Knowledge possession & 0.881 & 0.078 & 0.487 & 00.312 & 0 \\
\hline Processing & 1.047 & 0.093 & 0.47 & 11.221 & 0 \\
\hline saving & 0.842 & 0.178 & 0.194 & 4.739 & 0 \\
\hline
\end{tabular}

Table 8. Statistics of independent variables, excluded from total model

\begin{tabular}{|c|c|c|c|c|c|}
\hline Collinearity statistics & Partial & Sig T & $\mathrm{t}$ & Beta in & Variable \\
\hline Tolerance & & & & & \\
\hline 0.954 & 0.123 & 0.245 & 1.17 & 0.09 & Knowledge transmission \\
\hline
\end{tabular}

\subsection{Confirmatory path analysis based on model of structural equations:}

In order to know about existence or nonexistence of any cause and effect relationship between variables of this research and to consider proportion of observed data with model of research, as it can be seed in the chart, output of software indicates suitability of processed structural model to be executed in structural equations of main hypothesis of study (ratio of $x 2$ to DF is less than 1 and as the result, $x 2$ is low). Structural model of research is fitted properly according to following table; in other words, observed data is correlated to model of research.

Table 9. Fitness criteria of structural model

\begin{tabular}{|c|c|c|c|c|c|}
\hline RMSEA & $\mathrm{IFI}$ & $\mathrm{NNFI}$ & $\mathrm{NFI}$ & $\mathrm{CFI}$ & $\mathrm{GFI}$ \\
\hline 0.007 & 0.92 & 0.92 & 0.89 & 0.92 & 0.89 \\
\hline
\end{tabular}

\section{Conclusion}

The target of this study is to define a relationship between knowledge management (knowledge possession, saving, processing and knowledge transmission) and customer relationship management in the Sales industry of Kosova. As the results showed, there was a direct and meaningful relation between three aspects of knowledge management (knowledge possession, saving, processing) and customer relationship management in these industry. Such this meaningful and direct relation indicated the importance of conception of employees about knowledge management in their organization.

The positive understanding of employees about "knowledge possession" has the most direct effect on customer relationship management in study sales industry. This aspect describes the method to obtain information and data as explicit knowledge and tacit knowledge. Explicit knowledge (obvious) can be multiplexed in words and figures and in the 
shape of data, formulations, details, manuals and others. Hidden knowledge (tacit) exists in the mind of people and appears deeply in actions, experiences, values and desires of people.

Namely to have a successful customer relationship management system, the customer data should be obtained, saved and recorded to be changed to information and knowledge. Generally, according to the results of this study it can be declared that if employees understand the importance of "knowledge possession", knowledge management system will be prospered and elevated. According to achievements, "saving" criterion as the third factor, has a positive effect on improvement of customer relationship management in sales industry of Kosova.

Achievements of this study, totally, show that knowledge management has a direct and positive relation with CRM in sales industry of Kosova. So, in order to reinforce the agents to perform knowledge management, following suggestions may be considered:

Operational and supreme managers and also administrative staff of banks should believe in important role of knowledge management in their organization and its effect on organizational success and on improvement of CRM, and try to use knowledge management in key issues of their organization and in their decisions. In this regard, training staff to make them familiar with proper methods will be fruitful. Enough attention of bank managers to intellectual capitals and execution of knowledge-base strategies to define these programs will be a successful effort to establish knowledge management.

\section{References}

Bennett, R., \& Gabriel, H. (1999). Organizational Factors and Knowledge Management within Large Marketing Departments: An Empirical Study. Journal of Management, 3(3), 212-215.

Brooking, A. (1999). Corporate Memory: Strategies for Knowledge Management. UK: International Thomson Business Press.

Costello, G. (1996). Knowledge Management in Strategic Alliances: the Role of Information Technology. Thesis(D.Phil), University of Oxford, UK.

Chen, J, Z. Zhu \& H.Y.Xie (2004), Measuring Intellectual Capital: A New Modeland Empirical Study, Journal Of Intellectual Capital, 5(1): 195-212.

Davenport, T. H. (1994). Saving IT's Soul: Human-Centered Information Management. Harvard BusinessReview, March-April 1994.

Davenport, T. H., \& Prusak, L. (1998). Working Knowledge: How Organizations Manage What They Know. Boston, MA: Harvard Business School Press.

Drucker, P. F. (1992, September-October). The New Society of Organizations. Harvard Business Review.

Drucker, P. F. (1993). Post-Capitalist Society. New York: HarperCollins.

Drucker, P. F. (2002, August). The Discipline of Innovation. The Innovative Enterprise.

Frappaolo, C. (2002). Knowledge Management. Oxford, UK: Capstone Publishing.

Gamble, P. R., \& Blackwell, J. (2001). Knowledge Management: A State of the Art Guide. London, UK: Kogan

Jantz, R., 2001, "Knowledge management in academic libraries: special tools and processes to supportinformation professionals", Reference Service Review,29,1,33-9. 
